\title{
Impact of habitat loss on the diversity and structure of ecological networks between oxyurid nematodes and spur- thighed tortoises (Testudo graeca L.)
}

Julieta Benítez-Malvido ${ }^{\text {Corresp., } 1}{ }^{2}$, Andrés Giménez ${ }^{2}$, Eva Graciá ${ }^{2}$, Roberto Carlos Rodríguez-Caro ${ }^{2}$, Rocío Ruiz de Ybáñez ${ }^{3}$, Héctor Hugo Siliceo-Cantero ${ }^{1}$, Anna Traveset ${ }^{4}$

${ }^{1}$ Laboratorio de Ecología del Hábitat Alterado, Instituto de Investigaciones en Ecosistemas y Sustentabilidad, Universidad Nacional Autónoma de México (UNAM), Morelia, Michoacán, Mexico

2 Departamento de Biología Aplicada, Facultad de Ciencias Experimentales, Universidad Miguel Hernández, Elche, Spain

3 Departamento de Sanidad Animal, Facultad de Veterinaria, Campus de Excelencia Internacional Regional "Campus Mare Nostrum"., Universidad de Murcia, Murcía, Spain

${ }^{4}$ Global Change Research Group, Institut Mediterrani d'Estudis Avançats (CSIC-UIB), Esporles, Mallorca, Spain

Corresponding Author: Julieta Benítez-Malvido

Email address: jbenitez@cieco.unam.mx

Habitat loss and fragmentation are recognized as affecting the nature of biotic interactions, although we still know little about such changes for reptilian herbivores and their hindgut nematodes, in which endosymbiont interactions could range from mutualistic to commensal and parasitic. We investigated the potential cost and benefit of endosymbiont interactions between the spur-thighed tortoise (Testudo graeca L.) and adult oxyurid nematodes (Pharyngodonidae order Oxyurida) in scrublands of southern Spain. For this, we assessed the association between richness and abundance of oxyurid species with tortoises' growth rates and body traits (weight and carapace length) across levels of habitat loss (low, intermediate, and high). Furthermore, by using an intrapopulation ecological network approach, we evaluated the structure and diversity of tortoise-oxyurid interactions by focusing on oxyurid species infesting individual tortoises with different body traits and growth rates across habitats. Overall, tortoise body traits were not related to oxyurid infestation across habitats. Oxyurid richness and abundance however, showed contrasting relationships with growth rates across levels of habitat loss. At low habitat loss, oxyurid infestation was positively associated with growth rates (suggesting a mutualistic oxyurid-tortoise relationship), but the association became negative at high habitat loss (suggesting a parasitic relationship). Furthermore, no relationship was observed when habitat loss was intermediate (suggesting a commensal relationship). The network analysis showed that the oxyurid community was not randomly assembled but significantly nested, revealing a structured pattern for all levels of habitat loss. The diversity of interactions was lowest at low habitat loss. The intermediate level, however showed the greatest snecialization, which indicates that individuals were
Peerj reviewing PDF (2018:1 133006:3:0:NEW 11 Oct 2019) 
infested by fewer oxyurids in this landscape, whereas at high habitat loss individuals were the most generalized hosts. Related to the latter, connectance was greatest at high habitat loss, reflecting a more uniform spread of interactions among oxyurid species. At an individual level, heavier and larger tortoises tended to show a greater number of oxyurid species interactions. We conclude that there is an association between habitat loss and the tortoise-oxyurid interaction. Although we cannot infer causality in their association, we hypothesize that such oxyurids could have negative, neutral and positive consequences for tortoise growth rates. Ecological network analysis can help in the understanding of the nature of such changes in tortoise-oxyurid interactions by showing how generalized or specialized such interactions are under different environmental conditions and how vulnerable endosymbiont interactions might be to further habitat loss. 


\section{Impact of habitat loss on the diversity and structure of ecological networks}

2 between oxyurid nematodes and spur-thighed tortoises (Testudo graeca $\mathbf{L}$.)

3

4 Julieta Benítez-Malvido ${ }^{1}$, Andrés Giménez ${ }^{2}$, Eva Graciá ${ }^{2}$, Roberto Carlos Rodríguez-Caro ${ }^{2}$,

5 Rocío Ruiz de Ybáñez ${ }^{3}$, Héctor Hugo Siliceo-Cantero ${ }^{1}$ and Anna Traveset ${ }^{4}$

7 ['Laboratorio de Ecología del Hábitat Alterado, Instituto de Investigaciones en Ecosistemas y

8 Sustentabilidad, Universidad Nacional Autónoma de México (UNAM), Morelia, Michoacán,

9 México.

10

$11{ }^{2}$ Departamento de Biología Aplicada, Facultad de Ciencias Experimentales, Universidad Miguel 12 Hernández, Elche, Spain.

13

$14{ }^{3}$ Departamento de Sanidad Animal, Facultad de Veterinaria, Campus de Excelencia Internacional 15 Regional “Campus Mare Nostrum”. Universidad de Murcia, Spain.

16

$17{ }^{4}$ Global Change Research Group, Institut Mediterrani d'Estudis Avançats (CSIC-UIB), Esporles, 18 Mallorca, Balearic Islands, Spain.

19

20 Corresponding author: jbenitez@cieco.unam.mx

21

22

23 


\section{ABSTRACT}

25 Habitat loss and fragmentation are recognized as affecting the nature of biotic interactions,

26 although we still know little about such changes for reptilian herbivores and their hindgut

27 nematodes, in which endosymbiont interactions could range from mutualistic to commensal and

28 parasitic. We investigated the potential cost and benefit of endosymbiont interactions between

29 the spur-thighed tortoise (Testudo graeca L.) and adult oxyurid nematodes (Pharyngodonidae order Oxyurida) in scrublands of southern Spain. For this, we assessed the association between richness and abundance of oxyurid species with tortoises' growth rates and body traits (weight and carapace length) across levels of habitat loss (low, intermediate, and high). Furthermore, by using an intrapopulation ecological network approach, we evaluated the structure and diversity of tortoise-oxyurid interactions by focusing on oxyurid species infesting individual tortoises with different body traits and growth rates across habitats. Overall, tortoise body traits were not related to oxyurid infestation across habitats. Oxyurid richness and abundance however, showed contrasting relationships with growth rates across levels of habitat loss. At low habitat loss, oxyurid infestation was positively associated with growth rates (suggesting a mutualistic oxyurid-tortoise relationship), but the association became negative at high habitat loss (suggesting a parasitic relationship). Furthermore, no relationship was observed when habitat loss was intermediate (suggesting a commensal relationship). The network analysis showed that the oxyurid community was not randomly assembled but significantly nested, revealing a structured pattern for all levels of habitat loss. The diversity of interactions was lowest at low

44 habitat loss. The intermediate level, however, showed the greatest specialization, which indicates that individuals were infested by fewer oxyurids in this landscape, whereas at high habitat loss individuals were the most generalized hosts. Related to the latter, connectance was greatest at 
47 high habitat loss, reflecting a more uniform spread of interactions among oxyurid species. At an

48 individual level, heavier and larger tortoises tended to show a greater number of oxyurid species

49 interactions. We conclude that there is an association between habitat loss and the tortoise-

50 oxyurid interaction. Although we cannot infer causality in their association, we hypothesize that

51 such oxyurids could have negative, neutral and positive consequences for tortoise growth rates.

52 Ecological network analysis can help in the understanding of the nature of such changes in

53 tortoise-oxyurid interactions by showing how generalized or specialized such interactions are

54 under different environmental conditions and how vulnerable endosymbiont interactions might

55 be to further habitat loss.

\section{Introduction}

58 As a consequence of diverse human activities, habitat loss and fragmentation in terrestrial

59 ecosystems have been generally considered as the main threats to the maintenance of

60

61

62

64 65 biodiversity worldwide (Brooks et al., 2002; Fahrig, 2003; but see Fahrig, 2019). This is because native species are susceptible to habitat degradation through local extinctions and the reduction in the size of their populations. One aspect of land-use change that could have an important impact on wild populations and biodiversity is the local extinction of native species caused by changes in the nature of biotic interactions, including both mutualistic (e.g., pollination and seed dispersal) and antagonistic (e.g., pests and pathogens) interactions (Harvell et al., 2002; Patz et al., 2004; Aguilar et al., 2006; Aguirre \& Tabor, 2008; Tompkins et al., 2011; Trumbore, Brando \& Hartmann, 2015; Pringle, 2016). The ecological costs of these changes constitute the loss of species and populations and ecosystem degradation (Harvell et al., 2002; Rizzo et al., 2002; Patz et al., 2004; Aguilar et al., 2006; Aguirre \& Tabor, 2008; Vurro, Bonciani \& Vannacci, 2010; 
70 Trumbore, Brando \& Hartmann, 2015; Pringle, 2016). There are other biotic interactions,

71 however, that have been little explored in the context of habitat loss and fragmentation, such as

72 commensal interactions in which one species benefits whilst the other receives neither benefit

73 nor damage. In some reptiles, for instance, the symbiotic relationships with hindgut oxyurid

74 nematodes (endosymbionts) have been categorized as commensal, mutualistic and/or parasitic

75 (O'Grady et al., 2005; O'Grady \& Dearing, 2006; Jacobson, 2007). In fact, for herbivorous

76 reptiles, hindgut oxyurids and their associated gut microbial community (e.g., bacteria) might be

77 parasitic while also playing a positive role in the digestion and assimilation of plant matter,

78 which shows host-parasite-nutrition relationships (Roca 1999; O'Grady et al., 2005; O'Grady \&

79 Dearing, 2006; Donaldson, Lee \& Mazmanian, 2016; Midha, Schlosser \& Hartmann, 2017).

80 Some studies have suggested a relationship between the kind of oxyurids and the feeding habits

81 of the reptile host. For instance, the Pharyngodonidae (order Oxyurida) nematodes are

82 endosymbionts typical of reptiles with herbivorous diets (Roca 1999; O'Grady et al., 2005;

83 O'Grady \& Dearing, 2006). Hindgut oxyurids are frequently found in chelonians and they are

84 generally considered to have a commensal or even a mutualistic interaction with their hosts and

85 are rarely pathogenic (Roca 1999; Mitchell \& Figueroa, 2005; Jacobson, 2007).

Habitat loss and fragmentation influence local climate, resource availability and also the

87 distribution, abundance and behaviour of wildlife species and could therefore change the ecology

88 of parasite and/or endosymbiont transmission (Kareiva, 1987; Patz et al., 2004; Aguirre \& Tabor,

89 2008; Fuentes-Montemayor et al., 2009; Benavides et al., 2012; Suzán et al., 2012; Benítez-

90 Malvido et al., 2016; Pringle, 2016). Furthermore, there is evidence that habitat loss and

91 fragmentation reduce individual fitness for several animal species (e.g, bats, primates, rodents,

92 toads, lizards and tortoises) through changes in individual body size, as well as decreased growth 
93 and reproduction (Patz et al., 2004; Amo, López \& Martín, 2007; Fuentes-Montemayor et al.,

94 2009; Janin , Léna \& Joly et al., 2011; Benavides et al., 2012; Rodriguez-Caro et al., 2013). In

95 disturbed habitats, less vigorous and stressed individuals are more vulnerable to parasite

96 infection, whereas an infected individual is more prone to be infected by secondary pathogen

97 species concurrently (Patz et al. 2004; Beldomenico \& Begon, 2009; Benavides et al., 2012).

98 The southeastern Iberian Peninsula, as well as other Mediterranean areas, has been an

99 important speciation hot spot and refuge for the survival of several plant and animal species

100 (Hewitt, 2011). Nevertheless, this region has historically been subjected to different human

101 pressures for centuries so that several native species are currently threatened at present because

102 of the increased conversion of natural habitats to agricultural and other land uses (Sánchez-

103 Zapata \& Calvo, 1999; Anadón et al., 2006, Anadón, Wiegand \& Giménez, 2012; Anadón et al.,

104 2012; Hewitt, 2011; Rodríguez-Caro et al., 2017). In this study, we exclusively used the

105 oxyurids (Pharyngodonidae) present in the hindguts of spur-thighed tortoises, Testudo graeca L.

106 (F. Testudinidae) in scrublands of southeastern Spain as a research model to determine whether

107 the level of habitat loss (low, intermediate and high) is associated with the incidence of oxyurids

108 and individual body traits (i.e., carapace length and tortoise weight) and growth rates. The

109 available information has shown that the abundance of $T$. graeca within its original distribution

110 range is strongly associated to environmental factors, such as rainfall and temperature, because

111 as ectotherms, terrestrial tortoises tend to react strongly to variations in their environment

112 (Kaspari \& Valone, 2002; Anadón et al., 2006, Anadón, Wiegand \& Giménez, 2012; Anadón et

113 al., 2012; Rodríguez-Caro et al., 2016). Furthermore, such factors have shown strong shifts in

114 fragmented landscapes when compared to continuous natural habitats in different ecosystems 
115 elsewhere (Fuentes-Montemayor et al., 2009; Janin, Léna \& Joly et al., 2011; Anadón, Wiegand

116 \& Giménez, 2012; Anadón et al., 2012; Laurance et al., 2017).

117 Nematodes are the main helminths infecting terrestrial chelonians, and most of them

118 belong to the orders Ascaridida and Oxyurida, which are transmitted by the orofaecal route and

119 sexual contact (Chávarri et al., 2012). Ascarid infections are associated with carapace

120 deformities and symptoms of upper respiratory tract disease for captive $T$. graeca individuals

121 (Rideout et al., 1987; Jacobson 2007); whereas no ascarid infections have been reported for wild

122 tortoise populations in the study region (Chávarri et al., 2012). In contrast, the role of oxyurids as

123 a limiting factor of tortoise populations is not well understood. In fact, oxyurids can be highly

124 prevalent and are considered to have an almost commensal relationship with their hosts (Roca,

125 1999; Jacobson 2007). In addition, oxyurid infections and prevalence increase with age and/or

126 the tortoise's size, as has been found for other vertebrates (Morand \& Poulin 1998; Arneberg

127 2002; Jacobson 2007; Benavides et al., 2012). For the study region, reductions in growth rates

128 have been reported for T. graeca in disturbed habitats as well as differences in nematode

129 communities between wild and captive tortoises (Chávarri et al., 2012; Rodríguez-Caro et al.,

130 2013). Thus, we expect that tortoises' body traits, growth rates, oxyurid infestation and their

131 interaction are sensitive to habitat loss and fragmentation.

132 Ecological networks are increasingly being used as a valuable tool for studying the

133 complexity of biotic interactions at a community level, including both mutualistic and

134 antagonistic interactions (Bascompte et al., 2003; Bascompte \& Jordano, 2007; Benítez-Malvido

135 \& Dáttilo, 2015; Zarazúa-Carbajal et al., 2016; Hernández-Martínez et al., 2018). Within a given

136 community, different organisms and animal species can interact with each other, which generates

137 complex ecological networks (Bascompte \& Jordano, 2007). A large number of studies have 
138 found no random structures in ecological networks, including nestedness (Bascompte et al.,

139 2003; Bascompte \& Jordano, 2007; Almeida-Neto et al., 2008). A network is considered nested

140 if species with fewer interactions (specialists) are connected with species with the most

141 interactions (generalists) in cohesive subgroups (i.e., more generalized networks) (Guimarães et

142 al., 2006; Bascompte \& Stouffer, 2009). Despite the importance and increased knowledge of

143 ecological networks in the literature, most studies have focused on mutualistic interactions (e.g.,

144 pollination and seed dispersal; Bascompte \& Jordano, 2013), whereas antagonistic and

145 commensal interactions involving animals and their pathogens and endosymbionts have received

146 less attention (however, see Kareiva, 1987; Benítez-Malvido \& Dáttilo, 2015; Zarazúa et al.,

147 2016; Hernández-Martínez et al., 2018).

148 The general aims of this study were the following: (1) to assess if the level of habitat loss alters

149 the local abundance, species composition, richness, and the diversity and structure of ecological

150 networks of oxyurids associated with $T$. graeca, as well as (2) to describe the interaction type

151 between tortoises and oxyurids (i.e., positive, neutral and/or negative) as indicated by the

152 tortoises' body traits and growth rates. We expected that tortoise's body traits, growth rates,

153 oxyurid communities and host-oxyurid interactions to vary with the level of habitat loss, with

154 landscapes of low habitat loss differing from the other landscapes considered (Patz et al., 2004;

155 Qian \& Ricklefs, 2006; Fuentes-Montemayor et al., 2009; Suzán et al., 2012). It is clear that

156 habitat degradation affects the nature of biotic interactions and ecosystems' function; for

157 herbivorous reptiles, however, there is a limited understanding of the role that hindgut nematodes

158 have on them. Furthermore, conventional community descriptors have not always been

159 successful in distinguishing among habitats with different levels of degradation, which indicates

160 that alterations of the structure and function of ecological communities might be unnoticed in 
161 conservation research that does not document and quantify species interactions through an

162 ecological network approach (Kareiva, 1987; Tylianakis et al., 2007; Kaiser-Bunbury \&

163 Blüthgen, 2015).

164

165 Material \& Methods

166 Study area

167 The study region covering the southeastern T. graeca Spanish population comprises

168 approximately $2600 \mathrm{~km}^{2}$ of semiarid coastal mountains between the Almeria and Murcia

169 provinces (longitude $\mathrm{N} 38^{\circ} 23$ to $\mathrm{N} 36^{\circ} 20^{\prime}$ and latitude $\mathrm{W} 0^{\circ} 30$ to $\mathrm{W} 2^{\circ} 20^{\prime}$; Fig. 1). The climate

170 of the region is semiarid with mild winters, hot summers and low rainfall (200 to $350 \mathrm{~mm} /$ year)

171 during the cooler months of the year. This region has been subjected to human intervention for

172 centuries (Hewitt, 2011). Land-use practices are among the most important factors, together with

173 climate, relief and lithology, for determining $T$. graeca presence within its distribution range in

174 southeastern Spain (Anadón et al., 2006). Such practices include traditional agricultural crops

175 (dry crops known as secanos), heavily intensified irrigated agricultural lands, and highways

176 (Anadón et al., 2006). Intensified agricultural practices and fires, as well as habitat reforestation

177 with pines, have been shown to negatively affect $T$. graeca growth, survival and population

178 viability (Anadón et al., 2006; Sanz-Aguilar et al., 2011; Rodríguez-Caro et al., 2013, 2016,

179 2017; Graciá et al., in press). Furthermore, in this mosaic of land-use practices, tortoise

180 populations require native scrubland patches larger than $\geq 1 \mathrm{~km}^{2}$ or $75 \%$ scrubland cover at the

181 landscape level to remain viable and prevent local extinctions (Anadón et al., 2006). The study

182 sites were located in landscapes with different levels of land use intensification, habitat loss and

183 fragmentation. Nevertheless, traditional agricultural crops (secanos), when not extensive, are 
184 recognized as suitable habitats for $T$. graeca populations, and therefore the level of habitat loss

185 was established according to the proportion of suitable habitat for tortoises in the landscape.

186 Each site and/or tortoise's population represents one square kilometre, which correspond to a

187 UTM (Universal Transverse Mercator) cell of $1 \times 1 \mathrm{~km}$. In this sense, the landscapes with low

188 habitat loss (sampling sites in Villaltas, Galera and Marinica) comprised on average $95 \%$ of

189 suitable habitat, including $84.59 \%$ scrubland and $10.75 \%$ of traditional agriculture. Landscapes

190 with intermediate habitat loss (Bas Norte, Sierrecica and Chinas) comprised $81.60 \%$ of suitable

191 habitat, including $62.21 \%$ scrubland and $19.39 \%$ traditional agriculture. Finally, landscapes

192 with high habitat loss (Palas, Bas Sur and Misiripalme) encompassed $76.26 \%$ of suitable habitat,

193 including $40.71 \%$ scrubland and $35.54 \%$ of traditional agriculture (Fig. 1). The loss of native

194 scrubland habitat, scrubland fragmentation and land use intensification are related between each

195 other. Native scrubland has been reduced by more than $50 \%$ in landscapes with high habitat

196 loss, whereas traditional agricultural fields (secanos) presented a threefold increase therein, when

197 compared to landscapes with low habitat loss. These changes in landscape configuration and

198 composition have been shown to affect resource distribution and availability, challenging the

199 maintenance of tortoises and other animal populations elsewhere (Anadón et al., 2006; Janin,

200 Léna \& Joly et al., 2011; Benítez-Malvido et al., 2016; Pringle 2016; Rodríguez-Caro et al., 201 2017). The probability of T. graeca encounter with less than $40 \%$ scrubland cover is very low 202 (Anadón et al., 2006).

203

204 The spur-thighed tortoises and the prevalence of oxyurid nematodes

205 The Dirección General de Gestión del Medio Natural de la Junta de Andalucía (SGB/FOA/AFR),

206 the Delegación General de Medio Natural de la Comunidad Autónoma de la Región de Murcia 
207 (AUT/ET/UND/48/2010) granted the permissions to sample the tortoises and oxyurids. The spur208 thighed tortoise (T. graeca) is a midsize (up to $46 \mathrm{~cm}$ in length, Werner et al., 2016) terrestrial 209 tortoise and one of the most widely distributed species of terrestrial tortoises. Although mostly 210 distributed throughout North Africa, the Middle East and part of Eastern Europe, there are some 211 small isolated populations in Western Europe (Graciá et al., 2017; Fig. 1). This tortoise species is 212 typically present in arid and semiarid scrublands. The diet of $T$. graeca is based on several parts 213 (i.e., leaves, flowers, fruits and twigs) of wild plants such as alfalfa (Medicago sativa), thistles 214 (e.g., Carthamus and Carlina), dandelion (Taraxacum), rosemary (Rosmarinus officinalis), etc. 215 (Andreu, Díaz-Paniagua \& Keller, 2000; El Mouden et al., 2006). Furthermore, tortoises may 216 disperse the seeds of the consumed plant species (Cobo \& Andreu, 1988; Andreu, Díaz-Paniagua 217 \& Keller, 2000). The tortoises' diet also includes animal carcasses, slugs and insects, mainly at 218 early life stages. Currently, wild populations of $T$. graeca are severely threatened throughout 219 their whole distribution range because of habitat loss and fragmentation, as well as over220 collection, principally in southeastern Spain (Anadón et al., 2006, 2012; Anadón, Wiegand \& 221 Giménez, 2012; Pérez et al., 2012).

222 From mid March to mid June of 2010, at nine different localities (three for each level of 223 habitat loss), the wild tortoises sighted were captured within standardized transects. Each of the 224 nine sites was visited five times; the sampling time lasted for approximately 2 hours 30 minutes 225 along ca. $1750 \mathrm{~m}$ individual transects. After sampling, specimens were marked, and the 226 following individual traits were recorded without harming the tortoises: sex, age estimated from 227 the carapace growth ring (Rodríguez-Caro et al., 2013, 2015), body weight (g) and carapace 228 length $(\mathrm{mm})$. Thereafter, a growth rate score per individual $\left(\mathrm{mm} \mathrm{year}^{-1}, k\right)$ was calculated using 229 the von Bertalanffy model, the most used to describe chelonians' growth (Zivkov et al., 2007; 
230 Macale, Scalici \& Venchi, 2009). This model assumes that the rate of growth declines with age

231 (Fabens, 1965) and allows estimating the growth of each individual from its birth to the current

232 measurement time. For further details, see Appendix 1.

233 For the study of oxyurid communities, individual freshly voided faecal samples were

234 obtained immediately following the handling of the animal or from the cloth bag where animals

235 were placed until they defecated. Thereafter, individuals were released in their capture sites,

236 whereas tortoise faecal samples were maintained at $4{ }^{\circ} \mathrm{C}$ until processed within $48 \mathrm{~h}$ of

237 collection. Firstly, a saline solution was added to the faeces, and under a microscope the adult

238 oxyurids were collected and counted (Mac Arthur et al. 2004; Traversa et al. 2005; Jacobson

239 2007; Origgi and Paré 2007). Secondly, all collected adult oxyurids were washed in distilled

240 water and subsequently stored in $70 \%$ ethanol. Thirdly, oxyurids were cleared in Amann

241 lactophenol solution and subsequently identified to the species level following several keys

242 (Petter 1966; Bouamer \& Morand, 2000, 2002, 2003 a, b, 2005, 2006; Bouamer, Morand \&

243 Bourgat, 2001 a, b, 2003; Bouamer, Morand \& Kara, 2003). The number of Oxyuridae eggs and

244 larvae present in the faeces were not considered in this study because it was not possible to

245 identify these immature stages to the species level (Traversa et al., 2005). Species identification

246 was necessary for the construction of the tortoise-oxyurid ecological networks. Nevertheless, the

247 prevalence of Oxyuridae eggs was the most abundant life stage since $97 \%$ of the sampled

248 individuals contained eggs in their faeces; whereas oxyurid larvae and adults were present in 36

$249 \%$ and $72 \%$ of the individuals, respectively. Faecal samples containing adult oxyurids always

250 had oxyurid eggs as well (Chávarri et al., 2012). The number of oxyurid eggs, larvae and adults

251 per captured tortoise ranged from 0 to 28319 , from 0 to 1183 , and from 0 to 5245 , respectively.

252 Overall, 14 adult oxyurid species (all within the Oxyurida Family Pharyngodonidae) were 
253 isolated in wild populations of $T$. graeca, including the following: Tachygonetria dentata, $T$.

254 longicollis, T. macrolaimus, T. conica, T. pusilla, T. numidica, T. robusta, T. setosa, T.

255 palearticus, T. seurati, Alaeuris numidica, Mehdiella stylosa, M. uncinata and M. microstoma.

256 We sampled a total of 66 wild tortoises from areas with low (26 individuals),

257 intermediate (20 individuals), and high (20 individuals) habitat loss. In landscapes with low

258 habitat loss, we recorded the following: 14 adult females, seven adult males, four subadults and

259 two juveniles. In landscapes with intermediate habitat loss, we recorded three adult females, six

260 adult males, seven subadults and four juveniles. Finally, for the landscapes with high habitat loss,

261 we recorded nine adult females, four adult males, five subadults and two juveniles. Adults were

262 considered as those individuals $>8$ years old, and subadults were those individuals 5-8 years old.

263 Juveniles were all those tortoises 1-4 years old (Sanz-Aguilar et al., 2011).

264

\section{Statistical analysis}

266 Because the levels of oxyurid infection and prevalence increase with age (Chávarri et al., 2012),

267 we performed the statistical tests, firstly, by pooling all sampled individuals (adults, subadults

268 and juveniles), and secondly, on adult tortoises exclusively. For tortoise density (individuals/ha)

269 we analysed the entire sampled population. The data were analysed through generalized linear

270 models (GLMs) by means of the program Statistica 7, and significance was set at the $\alpha=0.05$

271 level. Firstly, to test if the level of habitat loss affected tortoise body traits, we used a one-way

272 ANOVA. Body traits values among individual tortoises varied greatly within and across habitat

273 types (e.g., body weight varied between $13-1220 \mathrm{~g}$ ). Therefore except for growth rates, values

274 were $\log (\mathrm{x}+1)$ transformed to improve normality. Because data on oxyurid species richness and

275 abundance were counts (Poisson distribution), we compared the levels of habitat loss by means 
276 of log-linear models with a chi-square measure of deviance. When overdispersion was found in

277 the error term of the model, the data were rescaled to make the tests more conservative (Crawley

278 1993, 2007). We also tested if oxyurid richness and abundance were related to tortoise density

279 across habitats using log-linear models.

280 Secondly, to test if tortoise body traits and growth rates were related to oxyurid species

281 richness and abundance across habitat loss categories (the categorical predictor variable with

282 three fixed factors), we compared the linear regression slopes among habitats by using one-way

283 ANCOVAs, with tortoise body traits and growth rates as the dependent variables and oxyurid

284 species richness and abundance as the independent ones (covariates). In total, we performed 12

285 one-way ANCOVAs, one for each of the two covariates (oxyurid species richness and

286 abundance), by again initially pooling all life stages and then for adults only.

287

288 Oxyurid nematode species dominance

289 To test whether the level of habitat loss affected oxyurid species relative abundance and/or

290 dominance, we constructed rank/abundance plots for the oxyurid communities present in

291 tortoises at each of the scrubland landscapes (low, intermediate and high habitat loss). For each

292 level of habitat loss, we plotted the relative abundance of each oxyurid species on a logarithmic

293 scale against the species' rank, ordered from the most to the least abundant species (Magurran

294 2004). To assess whether oxyurid species were evenly distributed (ecological evenness) across

295 the levels of habitat loss, we compared the slopes of the rank/abundance plots by means of an

296 ANCOVA. The species evenness of a given community is reflected in the slope of the line that

297 fits the rank/abundance plot (i.e., logarithmic series relationship). A steep slope indicates low

298 evenness since the high-ranking species are more abundant than the low-ranking species. A 
299 gentle slope indicates higher evenness because species abundances are more similar (Magurran 300 2004).

301

302 Patterns of species interactions by using a network approach

303 We used a network approach to investigate the structure of individual-based tortoise-oxyurid

304 networks and their underlying mechanisms. Only individuals with adult oxyurids were

305 considered in the interaction network analysis, mainly adult and subadult tortoises. The number

306 of infected tortoises in the three landscapes were 20, 13 and 15, for low, intermediate and high

307 habitat loss, respectively.

308 Firstly, we included the presence of different oxyurid species infecting $T$. graeca

309 individuals in each of the landscapes (low, intermediate and high habitat loss) as independent

310 interaction networks. We thus constructed three weighted interaction networks, one for each of

311 the habitat loss conditions. Each individual-based tortoise-oxyurid network was built by an

312 adjacency matrix $\boldsymbol{A}$, where $a_{i j}=$ the number of interactions from an individual tortoise $j$ by the

313 oxyurid species $i$, or otherwise 0 (i.e., the absence of interaction). Thus, in these networks,

314 oxyurid species and tortoises are depicted as nodes, and their interactions are represented by

315 links describing the use of tortoise individuals by oxyurid species. Thereafter, we tested if such

316 networks were nested, a pattern in which oxyurid species with fewer interactions (specialists) are

317 connected with tortoise individuals with the most interactions (generalists) in cohesive

318 subgroups. We used the WNODF metric (weighted nestedness metric based on overlap and

319 decreasing fill; Almeida-Neto et al., 2008; Almeida-Neto \& Ulrich, 2011) to estimate the

320 nestedness value of the networks by using ANINHADO software (Guimarães \& Guimarães,

321 2006). The $W N O D F$ metric evaluates whether or not the oxyurids of less selective tortoises 
322 represent subsets of the tortoises that are colonised by a broader number of oxyurids (i.e., species

323 and individuals) for each habitat type. This metric ranges from 0 (no nestedness) to 100 (perfect

324 nestedness). It reduces the chance of overestimating the degrees of nestedness in ecological

325 networks and is less prone to Type I statistical error (Bascompte \& Jordano, 2013). We

326 estimated the significance of nestedness with a Monte Carlo procedure, generating 1000 random

327 matrices from the original matrix by using the Null Model II (Bascompte et al., 2003). In this

328 null model, the probability of occurrence of an interaction is proportional to the number of

329 interactions of both oxyurid species and tortoise individuals (Bascompte et al., 2003). Secondly,

330 we considered other network parameters in the analysis for each habitat type as follows (Kaiser-

331 Bunbury \& Blüthgen 2015): (i) connectance (the proportion of realized links from the pool of all

332 possible links between the species of a network). Higher connectance indicates greater

333 community stability, reflecting a more uniform spread of interactions among the species in the

334 community; and (ii) interaction diversity (ID). This metric is derived from the Shannon diversity

335 index and ranges from 0 (no diversity) to infinity (Blüthgen, Menzel \& Blüthgen, 2006).

336 Interaction diversity is the quantitative analogue to the total number of links. Higher ID implies

337 higher community stability. Finally, we considered (iii) the specialization index or resource

338 selectivity at the network level $\left(H_{2}{ }^{\prime}\right)$. This selectivity index ranges from 0 (extreme

339 generalization) to 1 (extreme specialization) and is highly robust regarding changes in sampling

340 intensity and the number of interacting species (Blüthgen, Menzel \& Blüthgen, 2006). High

341 specialization indicates the high dependency of each oxyurid species on a few exclusive tortoise

342 partners. Low specialization indicates higher functional redundancy (Kaiser-Bunbury \&

343 Blüthgen, 2015).

344 In addition, by using GLMs, we tested if tortoise body traits and growth rates explained 
345 network parameters at the individual level for each habitat type (Kaiser-Bunbury \& Blüthgen

346 2015). We used species-degree (the number of oxyurid species infecting each tortoise) and

347 species-specialization (i.e., Blüthgen's $d$ ', a measure of the exclusiveness of a species' partner

348 spectrum compared with other species in the network, sensu Kaiser-Bunbury \& Blüthgen 2015)

349 as response variables. Species with low species-level specialization indicate opportunistic partner

350 selection compared with other species in the network. For the parameter species-degree, a

351 Poisson type error was used with a log-link function, while for species-specialization, simple

352 linear regression models with Gaussian type errors were used. Network features and plots were

353 obtained by using the Bipartite package in ' $\mathrm{R}$ ' (Dormann, Gruber \& Group, 2011; R

354 Development Core Team, 2014).

355

356 Results

357 Overall, we found that the level of habitat loss affected tortoise-oxyurid interactions with

358 consequences for tortoise growth rates, though not for tortoise weight and carapace length (Table

359 1). Moreover, tortoise density was not related to the richness and abundance of oxyurids. Not all

360 sampled tortoises were infested by adult oxyurids across landscapes, with $27 \%$, $35 \%$, and $25 \%$

361 of individuals being free from oxyurids, in low, intermediate and high habitat loss, respectively.

362 The number of oxyurid species varied between 0 to10 species across tortoises.

363

364 Habitat loss, body traits and prevalence of oxyurid nematodes

365 On the one hand, the one-way ANOVAs and the analysis of deviance showed, through pooling

366 all life stages and by considering only adults, that the level of habitat loss had no significant

367 effect on tortoise body traits and density, nor on oxyurid richness and abundance (Table 1). On 
368 the other hand, species richness and the abundance of oxyurids were significantly associated with

369 growth rates depending on the level of habitat loss, which was evaluated both by pooling all life

370 stages and then focusing on adults. Considering all life stages, the ANCOVA tests showed a

371 significant, positive association between oxyurid species richness with tortoise growth rates, but

372 only in landscapes with low habitat loss, as shown by the habitat loss level $x$ oxyurid species

373 richness interaction term (richness, $F_{2,58}=3.46, P=0.038$ ) (Fig. 2). Considering adult tortoises

374 only, oxyurid infestation and growth rates were not consistently associated across habitat types

375 (Fig. 2). In landscapes with high habitat loss, tortoises sustained greater growth rates than those

376 with low and intermediate habitat loss (richness, $F_{1,2}=6.39, P=0.0042$; abundance, $F_{1,2}=$

$3774.42, P=0.019$ ), whereas the habitat loss level $x$ oxyurid infestation interaction term was

378 significant for both species richness $\left(F_{2,35}=6.17, P=0.0051\right)$ and oxyurid abundance $\left(F_{2,35}=\right.$

$3794.24, P=0.022$ ) (Fig. 2). While growth rates were positively associated to oxyurid infestation in

380 landscapes with low habitat loss, the opposite was found in landscapes with high habitat loss; at

381 intermediate habitat loss, no association existed between the two variables (Fig. 2).

382

383 Habitat loss and oxyurid nematode species dominance

384 The oxyurid community for the three levels of habitat loss followed a log series model of a small

385 number of abundant species and a large proportion of rare species. The adult oxyurids most

386 commonly found in the faeces were of the species $T$. dentata and T. longicollis (Fig. 3). The

387 following patterns emerged in the rank-abundance plots: (1) all levels of habitat loss showed the

388 same dominant oxyurid species; (2) although rare species changed ranks across the three levels

389 of habitat loss, they were consistently the same species; and (3) the landscapes with high habitat

390 loss presented one exclusive species, T. seurati, whereas T. palearticus was absent from this 
391 landscape type (Fig. 4). The slope analysis in the ANCOVA showed that oxyurid relative

392 abundance differed significantly across habitats with more rare species at low habitat loss $\left(F_{2,33}\right.$ $393=28.28, P<0.001)$. Furthermore, the slope at low habitat loss is significantly steeper than the

394 slopes at intermediate and high habitat loss, as shown by the habitat loss level x oxyurid species 395 rank interaction term $\left(F_{2,33}=13.93, P<0.001\right)$, which indicates that oxyurid species are more 396 evenly distributed in the landscapes with intermediate and high habitat loss than in the 397 landscapes at low habitat loss (Fig. 3).

398

399

\section{Network structure}

400 The size of our networks (hereafter referred to as tortoise-oxyurid networks) was similar in the 401 number of oxyurid species among landscapes, suggesting that $T$. graeca maintains a stable 402 community of these oxyurids at the three levels of habitat loss (Table 2 and Fig. 4). The lowest 403 diversity of interactions (ID), indicating lower community stability, was at low habitat loss. In 404 contrast, the intermediate level of habitat loss showed the greatest specialization level $\left(H_{2}{ }^{\prime}\right)$, 405 implying that individuals were infested by fewer oxyurids in these landscapes, whereas 406 individuals were the most generalized (i.e., showing higher functional redundancy) at high 407 habitat loss. This agrees with the greater connectance in such habitats, reflecting a more uniform 408 spread of interactions among oxyurid species in the community at high habitat loss (Table 2 and 409 Fig. 4). The three levels of habitat loss showed a significant nested pattern of interactions, though 410 the landscapes with intermediate habitat loss exhibited the greatest nestedness values (Table 2). 411 Furthermore, at the individual network level, body traits and growth rates explained to some 412 extent network parameters (Table 2). Consistently in all habitats, heavier and larger tortoises 413 showed a significantly positive relationship with species-degree, i.e., with species richness of 
414 oxyurids in an individual, but not with species-specialization ( $d$ '). Moreover, species-degree

415 tended to increase with both tortoise weight and carapace length in low (weight, $\chi^{2}=5.76$, $\mathrm{df}=1$,

$416 P=0.016$; length, $\chi^{2}=6.01, \mathrm{df}=1, P=0.014$ ), intermediate (weight, $\chi^{2}=6.88, \mathrm{df}=1, P=$

417 0.0087; length, $\left.\chi^{2}=13.42, \mathrm{df}=1, P=0.0002\right)$ and high habitat loss (weight, $\chi^{2}=4.33$, df $=1, P=$

418 0.037). In this case, carapace length was positively related to species degree, though not

419 significantly. In contrast, species-degree was related to individual growth rates only in

420 landscapes with low levels of habitat loss $\left(\chi^{2}=6.65, \mathrm{df}=1, P=0.01\right)$, indicating that tortoises

421 that grow faster interact with more oxyurid species in this habitat.

422

423 Discussion

424 Overall, the level of habitat loss and the conveyed environmental and land use changes were

425 found to affect some aspects involved in the ecological interactions (e.g., at the population and

426 individual level) between the spur-thighed tortoises and their adult hindgut oxyurids. Oxyurid

427 infestation showed differential association only with hosts' growth rates, across levels of habitat

428 loss (Amo, López \& Martín, 2007; Janin, Léna \& Joly et al., 2011; Benavides et al., 2012). A

429 possible explanation is that body weight and carapace length are strongly correlated to tortoise's

430 age (Rodríguez-Caro et al. 2013), and age classes were not homogeneously distributed across

431 landscapes, which lead to great variability among sites. Conversely, individual growth rate

432 depends on the relation between age and size and therefore is not affected by age distribution

433 among populations (Appendix 1). Furthermore, larger and heavier tortoises were infected by

434 more oxyurid species. These changes were evident in spite of the similar oxyurid communities in

435 terms of species richness and composition across landscapes. In general, the association of

436 oxyurid infestation with growth rates was related to the level of habitat loss, ranging from 
437 positive, to neutral, to negative, for landscapes encompassing low, intermediate and high habitat

438 loss, respectively (Amo, López \& Martín, 2007; Janin, Léna \& Joly et al., 2011).

439

440 Habitat loss and the costs and benefits of oxyurid nematode infestation

441 The modification of the original scrubland vegetation by anthropogenic activities produces

442 strong shifts in the spatial configuration of the natural landscapes, as well as on their physical

443 (e.g., rainfall and temperature) and biological environments (e.g., vegetation structure, species

444 diversity and resources availability) (Patz et al., 2004; Qian \& Ricklefs, 2006; Amo, López \&

445 Martín, 2007; Janin , Léna \& Joly et al., 2011; Suzán et al., 2012; Pringle 2016). These

446 environmental shifts may occur at multiple spatial and temporal scales, which affect complex

447 species interactions, including host-oxyurid interactions of any kind (e.g., positive, negative

448 and/or neutral) in the case of herbivorous reptiles (Harvell et al., 2002; Amo, López \& Martín,

449 2007; Tylianakis et al., 2007; Janin, Léna \& Joly et al., 2011; Benavides et al., 2012; Benítez-

450 Malvido et al., 2016; Benítez-Malvido, Lázaro \& Ferraz, 2018; Hernández-Martínez et al.,

451 2018). Although our findings represent the standing incidence of adult oxyurids in T. graeca

452 tortoises (i.e., a single observation in time), we detected that changes in landscape configuration,

453 exemplified by the amount of suitable habitat, influenced some aspects of host-oxyurid

454 interactions as revealed by differences in oxyurid infestation levels, oxyurid species ecological

455 evenness, tortoises' growth rates and by differences in the networks' structure. There is evidence

456 showing that the most disturbed and homogenized landscapes (e.g., highly degraded landscapes)

457 are more susceptible to pest and pathogen invasions because human activities facilitate the

458 movement of exotic/invasive species to new areas and provide the conditions for their

459 establishment. An additional reason is that hosts might change their behavioural and 
460 physiological ecology (Patz et al., 2004; Qian \& Ricklefs, 2006; Amo, López \& Martín, 2007;

461 Janin, Léna \& Joly et al., 2011; Tompkins et al., 2011; Suzán et al., 2012). Another factor

462 influencing pathogen transmission and infestation, not detected in the present study, is host

463 population density (Arneberg, 2002). Therefore, the type of endosymbiont interaction (positive,

464 negative and/or neutral) between tortoises and hindgut oxyurids seems to depend on the

465 environmental context, in which differences in resource availability (e.g., host food type and

466 habitat structure) across habitats could be driving the observed variations among them

467 (Tompkins et al., 2011; Pringle, 2016). Large oxyurid infestation was negatively associated with

468 growth rate for adult tortoises in landscapes at high habitat loss, suggesting a parasitic interaction

469 (Fig. 3). Only under unusual circumstances, such as reptiles kept in captivity, are oxyurids

470 pathogenic (Jacobson 2007; Chávarri, et al. 2012). High habitat loss and fragmentation (extreme

471 conditions) might have lowered the capacity of tortoises to cope with a parasite infection in more

472 challenging conditions; alternatively, those individuals with low growth rates might have poorer

473 acquired immunity to oxyurids (Amo, López \& Martín, 2007; Janin, Léna \& Joly et al., 2011).

474 Recording oxyurids at all life stages in feces is indicative that oxyurids have been inhabiting

475 tortoise's hindguts long enough to complete their life cycles, and therefore, probably affecting

476 some aspects of tortoise's fitness (Jacobson 2007). Our results also showed, however, that high

477 oxyurid species richness and abundance in tortoises are positively related with growth rates at

478 low habitat loss, which suggests that oxyurid infestation could play a positive role in the

479 digestion and thus assimilation of plant matter, possibly indicating a mutualistic interaction

480 (Roca, 1999; Mitchell \& Figueroa, 2005; O'Grady et al., 2005; O'Grady \& Dearing, 2006;

481 Jacobson, 2007). Furthermore, at low habitat loss, tortoises could have a greater foraging range,

482 i.e., could show higher resource seeking activity enhancing a faster growth though 
483 simultaneously being exposed to greater oxyurid infection, regardless of their

484 parasitic/commensal/mutualistic nature (Amo, López \& Martín, 2007; Janin, Léna \& Joly et al.,

485 2011). Finally, tortoises within landscapes at intermediate habitat loss showed no significant

486 relationship between oxyurid infestation and growth rates, suggesting a commensal interaction in

487 which oxyurids had no apparent influence on tortoises' growth. Alternatively, tortoise hosts in

488 these landscapes might be able to sufficiently allocate resources for growth and parasite

489 resistance so that parasite acquisition and resistance balanced out.

490

In contrast to what might be expected, the ANCOVA showed that overall growth rates

491

were greater at high habitat loss for adult tortoises than at low habitat loss. In this context, some

492

native animal species are able to persist in degraded lands through morphological, physiological

493

and behavioural adjustments (Isabirye-Basuta \& Lwanga, 2008; Tompkins et al., 2011).

494 Terrestrial tortoises are ectotherms and therefore may strongly react to environmental changes

495 (Kaspari \& Valone, 2002; Anadón et al., 2006). It is possible that reduced scrubland vegetation

496

cover (greater canopy openness) in landscapes with high habitat loss aid tortoises in more

497

effectively regulating their body temperatures (Row \& Blouin-Demers, 2006; Poulin \& George-

498 Nascimento, 2007; Sato et al., 2014). In addition, in some reptile species, an adequate

499 thermoregulatory behaviour has been found to optimize the digestive performance, which in turn

500 can affect growth rates (Avery et al., 1993; Anguilletta, Hill \& Robson, 2002). Further studies

501 should consider other indicators of habitat loss on the resource availability for tortoises and the

502 impact on their populations, such as survival and reproductive success (Rodríguez-Caro et al.,

503 2013).

504 For the present study region, habitat loss and fragmentation have been found to

505 negatively affect the persistence of tortoise populations, but also the presence of native scrubland 
506 habitat in the vegetation matrix has been reported to enable $T$. graeca to persist in anthropogenic

507 landscapes (Anadón et al., 2006). There are no base line studies, however, that help us to

508 precisely determine the overall impact of land-use change in $T$. graeca populations because this

509 region has been modified for many centuries by anthropogenic activities of distinct magnitude

510 and intensity (Hewitt, 2011). Therefore, long-term studies on T. graeca population dynamics

511 and oxyurid infestation dynamics and their consequences (in survival, growth rates and

512 reproduction) are crucial for understanding habitat loss processes in population's viability, as

513 well as the wide-ranging role of oxyurid endosymbiotic interactions in tortoises.

514 Furthermore, it has been indicated that long-term studies are crucial for understanding the

515 impact of sporadic natural disturbances and/or catastrophic events (e.g., flooding, fire and

516 drought) on disease emergence, virulence and transmission (e.g., infection cycles) as well as on

517 overall host health (Baldemonico \& Begon, 2009; Tompkins et al., 2011; Zarazúa-Carbajal et al.,

518 2016; Hernández-Martínez et al., 2018). The latter might apply as well for nematode

519 endosymbionts. This information is relevant for the management of wild $T$. graeca populations

520 and cannot be obtained in short-term studies, such as the present one. For instance, the

521 information gathered in the present study was obtained during the spring months when resource

522 availability is high (i.e., with several plant species blooming and fruiting). There is no

523 information, however, on the prevalence and intensity of oxyurid infestation during seasons

524 when food sources are scarce, nor between years, nor on the consequences for tortoise

525 populations (Tompkins et al., 2011; Benavides et al., 2012).

526

527 Ecological networks in the management of spur-thighed tortoise populations

528 The oxyurid community infesting $T$. graeca populations was not randomly assembled but nested, 
529 revealing a structured pattern for all levels of habitat loss. Tortoise-oxyurid network properties

530 appear to be maintained in landscapes with contrasting levels of habitat loss, despite differences

531 in species dominance, as well as host number and quality (tortoises' sex, age and size). Our study

532 contributes to the understanding of the structure of ecological interactions in contrasting

533 landscapes. Within the same host population, we can often find both more selective (those

534 individuals colonized by a few oxyurid species) or more opportunistic (those individuals

535 colonized by many oxyurid species) individuals. Some network distribution metrics, such as $I D$

536 and $\mathrm{H}_{2}^{\prime}$, may be suitable indicators for detecting human-induced changes in some endosymbiotic

537 interactions (e.g., mutualistic, commensal and parasitic), including tortoise-oxyurid interactions

538 (Kareiva, 1987; Tylianakis, et al., 2007; Kaiser-Bunbury \& Blüthgen, 2015). For instance, theory

539 predicts positive correlations between host population density and/or body mass, as well as

540 parasite species richness (Morand \& Poulin, 1998; Arneberg, 2002). This relationship could only

541 be detected at the individual network level where tortoise body mass (i.e., weight) was associated

542 with the number of oxyurid species interactions.

543 We found that as habitat loss increases host specificity decreases. In other words, hosts

544 are infested by a wider array of oxyurids, making tortoises more vulnerable in an already

545 resource-limited environment in case the oxyurid infestation turns out to be parasitic. The greater

546 nested pattern in landscapes with intermediate and high habitat loss may also imply that oxyurids

547 can be more easily transmitted through the entire network, something that would be less likely if

548 the network had a more modular structure (i.e., consisting of very specialized host-oxyurid

549 interactions).

550 It is worth noting, however, that the lack of identification of oxyurid eggs and larvae

551 could have affected our results in several ways. For instance, oxyurid species richness might be 
552 underestimated, and, thus, some network parameters might have been misinterpreted. The use of

553 adult oxyurids, however, made our study more conservative, as it was also inconvenient

554 considering all oxyurid eggs and larvae as "single species" in our ecological networks.

555 Furthermore, the positive host-parasite-nutrition relationships might be stronger in adult oxyurids 556 given their more developed gut microbial community; whereas adult oxyurids might, as well, be

557 more pathogenic than eggs and larvae (Jacobson, 2007).

558

\section{Conclusions}

560 We aimed to understand the ways habitat loss affected spur-thighed tortoise populations

561 and to link habitat loss and tortoise-oxyurid interactions by using a network approach. Our

562 findings indicate that the level of habitat loss is associated with growth rates and host-

563 endosymbiont interactions; in this sense, this study is the first to provide the structure of such

564 networks. Animals, at any stage of their life cycles, are subject to infestation by many different

565 organisms that may modify, improve or interrupt the vital functions that affect their fitness (Patz

566 et al., 2004; Aguirre \& Tabor, 2008; Suzán, et al., 2012; Pringle, 2016). Moreover, molecular

567 studies -based on barcoding- would be very useful for identifying eggs and larvae and therefore,

568 to completely describe the oxyurid species conforming the nematode community in the spur-

569 thighed tortoise hindgut (Jacobson 2007 a, b; Origgi \& Paré 2007). On the one hand, the rapid

570 degradation of natural habitats might cause a large proportion of species and populations to be

571 vulnerable to disease, and native and exotic pathogens could become a threat for both plant and

572 animal communities (Anderson et al., 2004; Patz et al., 2004; Vurro, Bonciani \& Vannacci,

573 2010; Tompkins et al., 2011; Benítez-Malvido, Lázaro \& Ferraz, 2018). On the other hand,

574 habitat degradation might also cause the loss of mutualistic and commensal interactions. 
575 Therefore, it is essential to understand the nature and dynamics of symbiotic interactions, the life

576 histories of the animal hosts and the effects of the local environmental conditions on all of them.

577

578

\section{Acknowledgements}

580 We warmly thank J. M. Lobato for his careful technical support and to P. M. Mojica and M.

581 Fernández for their help with sampling tortoises. We are also very grateful to M. Chávarri for the 582 isolation and identification of oxyurid species. An anonymous reviewer made very valuable 583 suggestions to previous versions of the manuscript.

584

\section{References}

586

Aguilar R, Ashworth L, Galetto L, Aizen MA 2006. Plant reproductive susceptibility to

587 habitat fragmentation: review and synthesis through a meta-analysis. Ecology Letters 9:968-980

588 doi:10.1111/j.1461-0248.2006.00927.x.

589 Aguirre AA, Tabor GM. 2008. Global Factors Driving Emerging Infectious Diseases

590 Impact on Wildlife Populations. Annals of the New York Academy of Sciences. 1149:1-3

591 doi:10.1196/annals.1428.052.

592 Almeida-Neto M, Guimaraes P, Guimaraes PR, Loyola RD, Urlich W. 2008. A

593 consistent metric for nestedness analysis in ecological systems: reconciling concept and

594 measurement. Oikos 117:1227-1239 doi: 10.1111/j.0030-1299.2008.16644.x.

595 Almeida-Neto M, Ulrich W. 2011. A straightforward computational approach for 596 measuring nestedness using quantitative matrices. Environmental Modelling \& Sofware 26: 173597 178. doi:10.1016/j.envsoft.2010.08.003. 
Amo, 1L, López P \& Martín, J. 2007. Habitat deterioration affects antipredatory behavior,

599 body condition, and parasite load of female Psammodromus algirus lizards. Canadian Journal of 600 Zoology 85:743-751. DOI: 10.1139/Z07-052.

601 Anadón JD, Giménez A, Martínez M, Martínez J, Pérez I, Esteve MA. 2006. Factors

602 determining the distribution of the spur-thighed tortoise Testudo graeca in South-East Spain: a 603 hierarchical approach. Ecography 29:339-346 doi.org/10.1111/j.2006.0906-7590.04486.x.

604 Anadón, JD, Wiegand T, Giménez A. 2012. Individual-based movement models reveals 605 sex-biased effects of landscape fragmentation on animal movement. Ecosphere 3:64 606 doi:10.1890/ES11-00237.1.

Anadón JD, Giménez A, Graciá E, Perez I, Fernández M, Fahd S, El Mouden H,

608 Kalboussi M, Jdeidi T, Larbes S, Rouag R, Slimani T, Znari M, Fritz U. 2012. Distribution of 609 Testudo graeca in the western Mediterranean according to climatic factors. Amphibia-Reptilia 610 33:285-296 DOI:10.1163/156853812X643710.

611 Anderson PK, Cunningham AA, Patel NG, Morales FJ, Epstein PR, Daszak P. 2004.

612 Emerging infectious diseases of plants: pathogen pollution, climate change and agrotechnology 613 drivers. Trends in Ecology and Evolution 19:535-544 doi.org/10.1016/j.tree.2004.07.021. 614 Andreu AC, Díaz-Paniagua C, Keller C. 2000. La tortuga mora (Testudo graeca L.) en 615 Doñana. Asociación Herpetológica Española, Barcelona. Anguilletta Jr, MJ, Hill T, Robson MA. 2002. Is physiological performance optimized by

617 thermoregulatory behavior?: a case study of the eastern fence lizard, Sceloporus undulatus.

618 Journal of Thermal Biology 27: 199-204 doi.org/10.1016/S0306-4565(01)00084-5. Arneberg P. 2002. Host population density and body mass as determinants of species

620 richness in parasite communities: comparative analyses of directly transmitted nematodes of 
621 mammals. Ecography 25: 88-94. doi.org/10.1034/j.1600-0587.2002.250110.x

622 Avery, HW, Spotila JR, Congdon JD, Fischer Jr. RU, Standora EA, Avery SB. 1993.

623 Roles of diet protein and temperature in the growth and nutritional energetics of juvenile slider

624 turtles, Trachemys scripta. Physiological Zoology 66:902-925

625 doi.org/10.1086/physzool.66.6.30163746.

626 Bascompte J, Jordano P, Melian CJ, Olesen J. 2003.The nested assembly of plant-animal

627 mutualistic networks. Proceedings of Natural Academy of Science of USA 100:9383-9387

628 doi.org/10.1073/pnas. 1633576100.

629 Bascompte J, Jordano P. 2007. Plant-animal mutualistic networks: the architecture of

630 biodiversity. Annual Review of Ecology Evolution and Systematics 38:567-593

631 doi.org/10.1146/annurev.ecolsys.38.091206.095818.

632 Bascompte J, Stouffer DF. 2009. The assembly and disassembly of ecological networks.

633 Philosophical Transactions of the Royal Society of Biology 364:1781-1787

634 DOI: $10.1098 /$ rstb.2008.0226

635 Bascompte J, Jordano P. 2013. Mutualistic Networks. Princeton University Press.

636 ISBN9781400848720.

637 Beldomenico PM, Begon M. 2009. Disease spread, susceptibility and infection intensity: 638 vivious circles? Trends in Ecology and Evolution 25:22-27 doi.org/10.1016/j.tree.2009.06.015.

639 Benavides JA, Huchard E, Pettorelli N, King AJ, Brown ME, Archer CE, Appleton CHC, 640 Raymond M, Cowishaw G. 2012. From parasite encounter to infection: multiple-scale drivers of 641 parasite richness in a wild social primate population. American Journal of Physical

642 Anthropology 147:52-63. doi.org/10.1002/ajpa.21627 
644 with their plant hosts determines the topological structure of ecological networks in different 645 ways. American Journal of Botany 102:1-8 doi.org/10.3732/ajb.1400303.

646 Benítez-Malvido J, Martínez-Falcón AP, Dáttilo W, González-DiPierro AM, Lombera-

647 Estrada R, Traveset A. 2016. The role of sex and age in the architecture of intrapopulation

648 howler monkey-plant networks in continuous and fragmented rainforests. Peer $J$ 649 doi:10.7717/peerj.1809.

650 Benítez-Malvido J, Lázaro A, Ferraz IDK. 2018. Effect of distance to edge and edge 651 interaction on seedling regeneration and biotic damage in tropical rainforest fragments: A long652 term experiment. Journal of Ecology doi:10.1111/1365-2745.13003.

653 Blüthgen N, Menzel F, Blüthgen N. 2006. Measuring specialization in species interaction 654 networks. BMC Ecology 6:12-18 doi:10.1186/1472-6785-6-9.

655 Bouamer S, Morand S, 2000. Oxyuroids of Palearctic Testudines: new

656 definition of the genus Thaparia Ortlepp 1933 (Nematoda: Pharyngodonidae), redescriptions of

657 T. thapari thapari, and descriptions of two species. Comparative Parasitology 67:169-180

658 https://www.cabdirect.org/cabdirect/abstract/20000809684.

659 Bouamer S, Morand S. 2002. Descriptions of Tachygonetria combesin. sp and

660 redescriptions of four species of Tachygonetria Wedl, 1862 (Nematoda: Pharyngodonidae), with

661 a new diagnosis of the genus. Systematic Parasitology 53:121-139

662 doi.org/10.1023/A:102044390

663 Bouamer S, Morand S. 2003a. Descriptions of two new species of the genus

664 Tachygonetria Wedl, 1862 (Nematoda-Pharyngodonidae) and discussion of the relationships 
665 among the species of the genus. Parasitology Research 91:68-73 doi.org/10.1007/s00436-003-

666 0932-4.

667 Bouamer S, Morand S, 2003 b. Phylogeny of Palaearctic Pharyngodonidae parasite

668 species of Testudinidae: a morphological approach. Canadian Journal of Zoology 81:1885-1893

669 doi.org/10.1139/z03-166.

670 Bouamer S, Morand S, 2005. Descriptions of two new species of the genus

671 Tachygonetria Wedl, 1862 (Nematoda, Pharyngodonidae) and redescriptions of five species

672 parasites of Palaearctic Testidinidae. Zoosystema 27:193-209 doi.org/10.1007/s00436-003-

$673 \quad 0932-4$.

674 Bouamer S, Morand S. 2006. Nematodes parasites of Testudinidae (Chelonia): list of

675 species and biogeographical distribution. Annales Zoologici, Warszáwa 56: 225-240

676 doi.org/10.3161/000345406778700775.

677 Bouamer S, Morand S. Bourgat R. 2001a. Oxyuroids of Palaeartic Testudinidae-new

678 definition for Alaeuris Seurat, 1918 (Nematoda: Pharyngodonidae) and redescription of Alaeuris

679 numidica (Seurat 1918). Journal of Parasitology 87:128-133 doi.org/10.1645/0022-

$6803395(2001) 087[0128: O O P T N D] 2.0 . C O ; 2$.

681 Bouamer S, Morand S, Bourgat R. 2001b. Redescription of Mehdiella microstoma and

682 description of Mehdiella petterae sp. n., with a new definition of the genus Mehdiella Seurat,

6831918 (Nematoda: Pharyngodonidae). Folia Parasitologica 48:132-138.

684 Bouamer S, Morand S, Kara M. 2003. Redescription of four species of Mehdiella from

685 Testudinidae, with a key to the species and discussion on the relationships among the species of

686 this genus. Parasite 10:333-342 doi.org/10.1051/parasite/2003104333. 
689 in the hotspots of biodiversity. Conservation Biology 16:909-923 doi.org/10.1046/j.1523-

$690 \quad 1739.2002 .00530 . x$.

691

Chávarri M, Berriatua E, Giménez A, Gracia E, Martinez-Carrasco C,

Ortiz JM, de Ybanez RR. 2012. Differences in helminth infections between captive and wild 693 spur-thighed tortoises Testudo graeca in southern Spain: A potential risk of reintroductions of

694 this species. Veterinary Parasitology 187:491-497 doi.org/10.1016/j.vetpar.2012.02.007.

695

Cobo M, Andreu AC. 1988. Seed consumption and dispersal by the spur-thighed tortoise 696 Testudo graeca. Oikos 51: 267-273 DOI: 10.2307/3565307. United Kingdom.

Crawley MJ. 2007. The R book. West Sussex: John Wiley and Sons. project.org. Arid Environments 64:422-435 doi.org/10.1016/j.jaridenv.2005.06.010. 
711 Ecology, Evolution and Systematics 34:487-515

712 doi.org/10.1146/annurev.ecolsys.34.011802.132419.

713 Fahrig L, Arroyo-Rodríguez V, Bennetta JR, Boucher-Lalonde V, Cazetta E, J. Currie D,

714 Eigenbrod F, Ford AT, Harrison SP, Jaeger JAG, Koper N, Martin AE, Martin JL, Metzger JP,

715 Morrison P, Rhodes JR, Saunders DA, Simberloff D, Smith AC, Tischendorf L, Vellend M,

716 Watling JI. 2019. Is habitat fragmentation bad for biodiversity? Biological Conservation

717 230:179-186 doi.org/10.1016/j.biocon.2018.12.026.

718 Fuentes-Montemayor E, Cuarón AD, Vázquez-Domínguez E, Benítez-Malvido J,

719 Valenzuela D, Andresen E. 2009. Living on the edge: roads and edge effects on animal

720 populations. Journal of Animal Ecology 78:857-865 http://hdl.handle.net/1893/16991.

721 Graciá E, Vargas-Ramírez M, Delfino M, Anadón JD, Giménez A, Fahd S, Corti C,

722 Jdeidi TB, Fritz U. 2017. Expansion after expansion: dissecting the phylogeography of the

723 widely distributed spur-thighed tortoise, Testudo graeca (Testudines: Testudinidae)

724 Biological Journal of the Linnean Society 121:641-654 doi.org/10.1093/biolinnean/blx007.

725 Graciá E, Rodríguez-Caro RC, Sanz-Aguilar A, Anadón JD, Botella F, García-García

726 AL, Wiegand T, Giménez A. (In press). Assessment of the key evolutionary traits that prevent

727 extinctions in human-altered habitats using a spatially explicit individual-based model.

728 Ecological modelling.

729 Guimarães PR Jr, Guimarães PR. 2006. Improving the analyses of nestedness for large

730 sets of matrices. Environmental Modelling Software 21:1512-1513

731 doi.org/10.1016/j.envsoft.2006.04.002. 
733 specialization in ant-plant mutualistic networks. Proceedings of the Real Society of Biological

734 Science 273:2041-2047 doi:10.1098/rspb.2006.3548.

735 Harvell C, Mitchell CE, Ward JR, Atizer S, Dobson AP, Ostfeld RS, Samuel MD. 2002.

736 Climate warming and disease risks for terrestrial and marine biota. Science 296:2158-2162. doi.

737 org/10.1126/science.1063699.

738 Hernández-Martínez J, Morales-Malacara JB, Alvarez-Añorve MY, Amador-Hernández

739 S, Oyama K, Avila-Cabadilla LD. 2018. Drivers potentially influencing host-bat fly interactions

740 in anthropogenic neotropical landscapes at different spatial scales. Parasitology 1-15.

741 doi.org/10.1017/S0031182018000732.

742 Hewitt GM. 2011. Mediterranean Peninsulas: The evolution of hotspots. In: Zachos FE,

743 Habel JC, eds. Biodiversity Hotspots. Distribution and Protection of Conservation Priority Areas.

744 Springer, Berlin. 123-147. ISBN 978-3-642-20992-5.

745 Isabirye-Basuta GM, Lwanga JS. 2008. Primate populations and their interactions with

746 changing habitats. International Journal of Primatology 29:35-48 doi.org/10.1007/s10764-008-

$747 \quad 9239-8$.

748 Jacobson ER. 2007. Parasites and parasitic diseases of reptiles. In: Infectious diseases and

749 pathology of reptiles. Jacobson ER. Ed. CRC Press. Florida USA. 571-666. ISBN 0-8493-2321-

$750 \quad 5$.

751 Janin A, Léna JP, Joly P. 2011. Beyond occurrence: body condition and stress hormone

752 as integrative indicators of habitat availability and fragmentation in the common toad. Biological

753 Conservation 144:1008-1016. doi.org/10.1016/j.biocon.2010.12.009.

754 Kaiser-Bunbury CN, Blüthgen N. 2015. Integrating network ecology with applied 
755 conservation: a synthesis and guide to implementation. AoB PLANTS 7: plv076;

756 doi:10.1093/aobpla/plv076.

757 Kareiva P. 1987. Habitat fragmentation and the stability of predator-prey interactions.

758 Nature 326:388-390. doi.org/10.1038/326388a0.

759 Kaspari M., Valone TJ. 2002. On ectotherm abundance in a seasonal environment-studies

760 of a desert ant assemblage. Ecology 83:2991-2996 doi.org/10.1890/0012-

$7619658(2002) 083[2991: O E A I A S] 2.0 . C O ; 2$.

762 Laurance WF, Camargo JL, Fearnside PM, Lovejoy TE, Williamson GB, Mesquita RCG,

763 Laurance SGW. 2017. An Amazonian rainforest and its fragments as a laboratory of climate

764 change. Biological Reviews 93:223-247 doi.org/10.1111/brv.12343.

765 Macale D, Scalici M, Venchi A. 2009. Growth, mortality, and longevity of the Egyptian

766 tortoise Testudo kleinmanni Lortet, 1883. Israeli Journal of Ecology and Evolution 55: 133-147.

767 doi.org/10.1560/IJEE.55.2.133.

768 McArthur S, Meyer J, Innis C. 2004. Anatomy and physiology. In: Medicine and surgery

769 of tortoises and turtles. McArthur S, Wilkinson R, Meyer J. Eds. ,Blackwell Publishing Ltd.,

770 Oxford, UK, 35-72. SBN: 978-1-405-10889-8.

771

Magurran AE. 2004. Measuring biological diversity. Oxford: Blackwell. ISBN 0-632-

$772 \quad 05633-9$.

773 Midha A, Schlosser J, Hartmann S. 2017. Reciprocal interactions between nematodes and

774 their microbial environments. Frontiers in Cellular and Infection Microbiology 7:144. doi:

$77510.3389 /$ fcimb.2017.00144.

776 Mitchell MA, Figueroa O. 2005. Clinical reptile gastroenterology. Veterinary Clinics:

777 Exotic Animal Practice 8: 277-298 doi.org/10.1016/j.cvex.2005.01.008. 
Morand S, Poulin R. 1998. Density, body mass and parasite species richness of terrestrial

779

780

781

782

783

784

785

786

787

788

789

790

791

792

793

794

795

796

797

798

799

800

mammals. Evolutionary Ecology 12:717-727 doi.org/10.1023/A:100653760

O’Grady SP, Morando M, Avila L, Dearing D. 2005. Correlating diet and digestive tract

specialization: Examples from the lizard family Liolaemidae. Zoology 108:201-210 doi.org/10.1016/j.zool.2005.06.002.

O'Grady SP, Dearing D. 2006. Isotopic insight into host-endosymbiont relationships in Liolaemid lizards. Oecologia 150:355-361 doi.org/10.1007/s00442-006-0487-z.

Origgi, F.C. and Paré, J.A. 2007. Isolation of pathogens. In: Infectious diseases and pathology of reptiles. Jacobson ER. Ed. CRC Press. Florida USA. 667-680). ISBN 0-8493-23215.

Jacobson ER. 2007. Parasites and parasitic diseases of reptiles. In: Infectious diseases and pathology of reptiles. Jacobson ER. Ed. CRC Press. Florida USA. 571-666. ISBN 0-8493-23215.

Patz JA, Daszak P, Tabor GM, Aguirre AA, Pearl M, Epstein J, Wolfe NA, Kilpatrick AM, Foufopoulos J, Molynex D, Bradley DJ, David J, Butler C. 2004. Unhealthy landscapes: policy recommendations on land use change and infectious disease emergence. Environmental health perspectives 112:1092-1098 doi.org/10.1289/ehp.6877.

Pérez I, Tenza, A, Martínez J, Anadón JD, Graciá E, Giménez A. 2012. Exurban sprawl increases the extinction probability of an endangered tortoise due to well-intentioned collections. Ecological Modelling 245:19-30 doi.org/10.1016/j.ecolmodel.2012.03.016.

Petter AJ. 1966. Équilibre des espèces dans les populations de nématodes parasites du colon des tortues terrestres. Mémories du Muséum National d'Histoire Naturelle. Série A, Zoologie, Paris 39:252. 
802 body mass. International journal for parasitology 37:359-364

803 doi.org/10.1016/j.ijpara.2006.11.009.

804 Pringle E. 2016. Orienting the Interaction Compass: Resource Availability as a Major 805 Driver of Context Dependence. Plos One DOI:10.1371/journal.pbio.2000891.

806 Qian H, Ricklefs RE. 2006. The role of exotic species in homogenizing the North 807 American flora. Ecology Letters 9:1293-1298 doi.org/10.1111/j.1461-0248.2006.00982.x.

808 R DEVELOPMENT CORE TEAM. 2014. R: A language and environment for statistical 809 computing. R Foundation for Statistical Computing, Vienna, Austria.

810 Rideout BA, Montali RJ, Phillips LG, Gardiner CH. 1987. Mortality of captive tortoises

811 due to viviparous nematodes of de genus Proatractis (family Atractidae). Journal of Wildlife

812 Diseases 23:103-108 doi.org/10.7589/0090-3558-23.1.103.

813 Rizzo DM, Garbelotto M, Davidson JM, Salaughter GW, Koike ST. 2002. Phytophtora

814 ramorum as the cause of extensive mortality of Querqus ssp. and Lothocarpus densiflorus in

815 California. Plant Disease 86:205-214 doi.org/10.1094/PDIS.2002.86.3.205.

816 Roca V.1999. Relación entre las faunas endoparásitas de reptiles y sus tipos de

817 alimentación. Revista Española de Herpetología 13:101-121.

818 Rodríguez-Caro RC, Gracía E, Anadón JD, Giménez A. 2013. Maintained effects of fire 819 on individual growth and survival rates in a spur-thighed tortoise population. European Journal 820 of Wildlife Research 59:911-913 doi.org/10.1007/s10344-013-0764-1.

821 Rodríguez-Caro R, Graciá E, Dos Santos RM, Anadón JD, Gimenez A. 2015. One scute 822 ring per year in Testudo graeca? A novel method to identify ring deposition patterns in tortoises. 823 Acta Herpetologica 10:77-84 doi.org/10.13128/Acta_Herpetol-14979. 
825 Density dependence, climate and fires determine population fluctuations of the spur-thighed

826 tortoise Testudo graeca. Journal of Zoology 300: 265-273 doi.org/10.1111/jzo.12379.

827 Rodríguez-Caro RC, Oedekoven CS, Graciá E, Anadón JD, Buckland ST, Esteve-Selma

828 MA, Martínez J, Giménez A. 2017. Low tortoise abundances in pine forest plantations in forest829 shrubland transition areas. Plos One doi.org/10.1371/journal.pone.0173485.

830 Row JR, Blouin-Demers G. 2006. Thermal quality influences effectiveness of

831 thermoregulation, habitat use, and behaviour in milk snakes. Oecologia 148:1-11

832 doi.org/10.1007/s00442-005-0350-7.

833 Sánchez-Zapata JA, Calvo JF. 1999. Raptor distribution in relation to landscape

834 composition in semi-arid Mediterranean habitats. Journal Applied Ecology 36:254-262

835 doi.org/10.1046/j.1365-2664.1999.00396.x.

836 Sanz-Aguilar A, Anadón JD, Giménez A, Ballestar R, Graciá,E, Oro D. 2011. Coexisting

837 with fire: the case of the terrestrial tortoise Testudo graeca in Mediterranean shrublands.

838 Biological Conservation 144:1040-1049 doi.org/10.1016/j.biocon.2010.12.023.

839 Sato CF, Wood JT, Schroder M, Michael DR, Osborne WS, Green K, Lindenmayer DB.

840 2014. Designing for conservation outcomes: the value of remnant habitat for reptiles on ski runs

841 in subalpine landscapes. Landscape Ecology 29: 1225-1236 doi.org/10.1007/s10980-014-0058-

8423.

843 Suzán G, Esponda F, Carrasco-Hernández R, Aguirre AA. 2012 Habitat fragmentation

844 and infectious disease ecology. In: Aguirre AP, Daszak, Ostfeld RS. ed. Conservation Medicine:

845 Applied cases of Ecological Health. Oxford University Press. ISBN 978-0-19-973147-3.

846 Tompkins DM, Dunn AM, Smith MJ, Telfer S. 2011.Wildlife diseases: 
847 from individuals to ecosystems. Journal of Animal Ecology 80:19-38 doi 10.1111/j.1365-

$848 \quad 2656.2010 .01742 . x$.

849 Traversa, D., Capelli, G., Iorio, R., Bouamer, S., Cameli, A., Giangaspero, A., 2005.

850 Epidemiology and biology of nematodofauna affecting Testudo hermanni, Testudo graeca and

851 Testudo marginata in Italy. Parasitological Research. 98: 14-20.

852 Trumbore S, Brando P, Hartmann H. 2015. Forest health and global

853 change. Science 349:814-818 doi.org/10.1126/science. Aac 6759.

854 Tylianakis JM, Tscharntke T, Lewis OT. 2007. Habitat modification alters the structure

855 of tropical host-parasitoid food webs. Nature 445:202-205 doi.org/10.1038/nature05429.

856 Vurro M, Bonciani B, Vannacci G. 2010. Emerging infectious diseases of crop plants in

857 developing countries: impact on agriculture and socio-economic consequences. Food Security

$858 \quad$ 2:113-132 doi.org/10.1007/s12571-010-0062-7.

859 Werner YL, Korolker N, Sion G \& Göçmen B. 2016. Bergmann's and Rensch's rules and 860 the spur-thighed tortoise (Testudo graeca). Biological Journal of the Linnean Society 117: 796861 811. doi.org/10.1111/bij.12717.

862 Zarazúa-Carbajal M, Saldaña-Vázquez RA, Sandoval-Ruiz CA, Stoner KE, Benitez-

863 Malvido J. 2016. The specificity of host-bat fly interaction networks across vegetation and 864 seasonal variation. Parasitology Research doi: 10.1007/s00436-016-5176-1.

865 Zivkov M, Ivanchev I, Raikova-Petrova G, Trichkova T. 2007. First data on the 866 population structure, growth rate and ontogenetic allometry of the tortoise Testudo hermanni in 867 eastern Stara Planina (Bulgaria) - Comptes Rendus de L'Academie Bulgare des Sciences 868 60:1015-1022. 
870

871

872

873

874 


\section{Figure legends}

877 Figure 1. The map shows the distribution of the spur-thighed tortoise (Testudo graeca) in the

878 Mediterranean basin. The wild populations sampled for the present study and their localities are

879 indicated with dots: Villaltas, Galera and Marinica, as landscapes with low habitat loss for

880 tortoises; Bas Norte, Sierrecica and Chinas, as landscapes with intermediate habitat loss; and

881 Palas, Bas Sur and Misiripalme, as landscapes with high habitat loss. These wild Spanish

882 populations of $T$. graeca cover approximately $2600 \mathrm{~km}^{2}$ of semiarid coastal mountains between

883 the Almeria and Murcia provinces.

884

885 Figure 2. Best-fit linear regressions, with $95 \%$ confidence intervals, between oxyurid nematode 886 infestation (i.e., species richness and abundance) and tortoises' (Testudo graeca) growth rates in 887 scrubland landscapes in southern Spain. Tortoises were present in landscapes sustaining different 888 levels of habitat loss (low, intermediate and high). (A and B) Tortoise populations at all life 889 stages. (C and D) Adult tortoise populations only. Significant relationships are indicated by $* P<$ 8900.01 an/or $* * P<0.001$. The values for the linear regression equation $(y=a+b x)$ and the 891 resulting $r$-values are indicated for each case.

893 Figure 3. Rank/abundance plots for the oxyurid nematode community infesting tortoises 894 (Testudo graeca) in scrubland landscapes with different levels of habitat loss (low, intermediate 895 and high) in southern Spain. For each landscape, the relative abundance of each nematode 896 species is plotted on a logarithmic scale against the species' rank, from the most to the least 897 abundant species. Nematodes included the following species: Alaeuris numidica (A. num), 898 Mehdiella stylosa (M. styl), M. uncinata (M. unci), M. microstoma (M. micro), Tachygonetria 
899 longicollis (T. long), T. dentata (T. dent), T. conica (T. coni), T. robusta (T. rob), T. macrolaimus

900 (T. mac), T. numidica (T. numi), T. setosa (T. set), T. palearticus (T. pale), T. pusilla (T. pusi),

901 and T. seurati (T. seur). Nematode species not found under all habitat loss conditions are in bold

902 red.

903

904 Figure 4. Quantitative bipartite plots of the tortoise-oxyurid species ecological networks for each 905 landscape encompassing different levels of habitat loss (low, intermediate and high) in southern

906 Spain. (A) Tortoise- oxyurid ecological network at low habitat loss. (B) Tortoise- oxyurid

907 ecological network at intermediate habitat loss. (C) Tortoise- oxyurid ecological network at high

908 habitat loss. The bar size represents the number of interactions each oxyurid species (black) had

909 with each individual tortoise (Testudo graeca) in the population (grey), and the linkage width

910 represents the proportion of oxyurid individuals involved in such interactions. 


\section{Table $\mathbf{1}$ (on next page)}

Tortoise traits, growth rates and oxyurid nematode infestation

Body traits (mean $\pm \mathrm{SE}$ ), density and oxyurid nematode infestation (i.e., species richness and abundance) of spur-thighed tortoise populations (Testudo graeca) at scrubland landscapes with different levels of habitat loss in southern Spain. The values in bold are those exclusively from adult tortoises. There was no significant difference among levels of habitat loss on any variable. 
1 Table 1. Body traits (mean $\pm \mathrm{SE}$ ), density and oxyurid nematode infestation (i.e., species

2 richness and abundance) of spur-thighed tortoise populations (Testudo graeca) at scrubland

3 landscapes with different levels of habitat loss in southern Spain. The values in bold are those

4 exclusively from adult tortoises. There was no significant difference among levels of habitat loss

5 on any variable.

\begin{tabular}{|c|c|c|c|}
\hline $\begin{array}{l}\text { Body traits and } \\
\text { nematode infestation }\end{array}$ & $\begin{array}{c}\text { Low } \\
(\mathrm{N}=26)(\mathrm{N}=\mathbf{2 1})\end{array}$ & $\begin{array}{c}\text { Intermediate } \\
(\mathrm{N}=20)(\mathrm{N}=\mathbf{9})\end{array}$ & $\begin{array}{c}\text { High } \\
(\mathrm{N}=20)(\mathrm{N}=\mathbf{1 3})\end{array}$ \\
\hline $\begin{array}{l}\text { Overall tortoise } \\
\text { density } \\
\text { (individuals/ha) }\end{array}$ & $2.57 \pm 1.19$ & $2.26 \pm 0.66$ & $0.83 \pm 0.07$ \\
\hline Weight (g) & $\begin{array}{l}431.79 \pm 83.04 \\
\mathbf{5 2 7 . 0 0} \pm \mathbf{4 7 . 9 0}\end{array}$ & $\begin{array}{l}267.36 \pm 59.41 \\
\mathbf{4 8 6 . 0 0} \pm \mathbf{7 5 . 7 8}\end{array}$ & $\begin{array}{l}410.10 \pm 91.13 \\
\mathbf{5 3 4 . 9 1} \pm \mathbf{5 9 . 9 5}\end{array}$ \\
\hline Carapace length & $129.95 \pm 6.86$ & $123.44 \pm 7.45$ & $132.00 \pm 7.84$ \\
\hline$(\mathrm{mm})$ & $131.12 \pm 4.01$ & $127.10 \pm 6.14$ & $128.45 \pm 5.45$ \\
\hline Growth rate $(\mathrm{mm}$ & $0.115 \pm 0.016$ & $0.085 \pm 0.019$ & $0.124 \pm 0.018$ \\
\hline year $^{-1}$ & $\mathbf{0 . 1 3 1} \pm \mathbf{0 . 0 1 4 9}$ & $0.123 \pm 0.019$ & $0.157 \pm 0.025$ \\
\hline Adult oxyurid & $2.59 \pm 0.567$ & $2.60 \pm 0.66$ & $3.55 \pm 0.66$ \\
\hline species richness & $3.82 \pm 0.54$ & $5.57 \pm 1.31$ & $5.27 \pm 0.90$ \\
\hline Abundance of adult & $303.63 \pm 184.20$ & $200.05 \pm 214.01$ & $360.30 \pm 214.01$ \\
\hline oxyurids & $480.82 \pm 308.32$ & $561.00 \pm 311.05$ & $614.27 \pm 468.36$ \\
\hline
\end{tabular}




\section{Table 2 (on next page)}

Tortoise-oxyurid network parameters

Tortoise-oxyurid ecological network attributes at two hierarchical levels in landscapes that differ in their levels of habitat loss in scrublands of southern Spain. 
1 Table 2. Tortoise-oxyurid ecological network attributes at two hierarchical levels in landscapes

2 that differ in their levels of habitat loss in scrublands of southern Spain.



Individual level

$($ mean $\pm \mathrm{SE})$

$\begin{array}{lrrr}\text { Specialization index } & 0.228 \pm 0.050 & 0.187 \pm 0.031 & 0.188 \pm 0.027 \\ \left(d^{\prime}\right) & & \\ \text { Number of } & 3.50 \pm 0.494 & 4.00 \pm 0.828 & 4.73 \pm 0.777 \\ \text { interactions (degree) } & & \end{array}$




\section{Figure 1}

Map of Testudo graeca tortoises sampling sites

The map shows the distribution of the spur-thighed tortoise (Testudo graeca) in the Mediterranean basin. The wild populations sampled for the present study and their localities are indicated with dots: Villaltas, Galera and Marinica, as landscapes with low habitat loss for tortoises; Bas Norte, Sierrecica and Chinas, as landscapes with intermediate habitat loss; and Palas, Bas Sur and Misiripalme, as landscapes with high habitat loss. These wild Spanish populations of $T$. graeca cover approximately $2600 \mathrm{~km}^{2}$ of semiarid coastal mountains between the Almeria and Murcia provinces. 


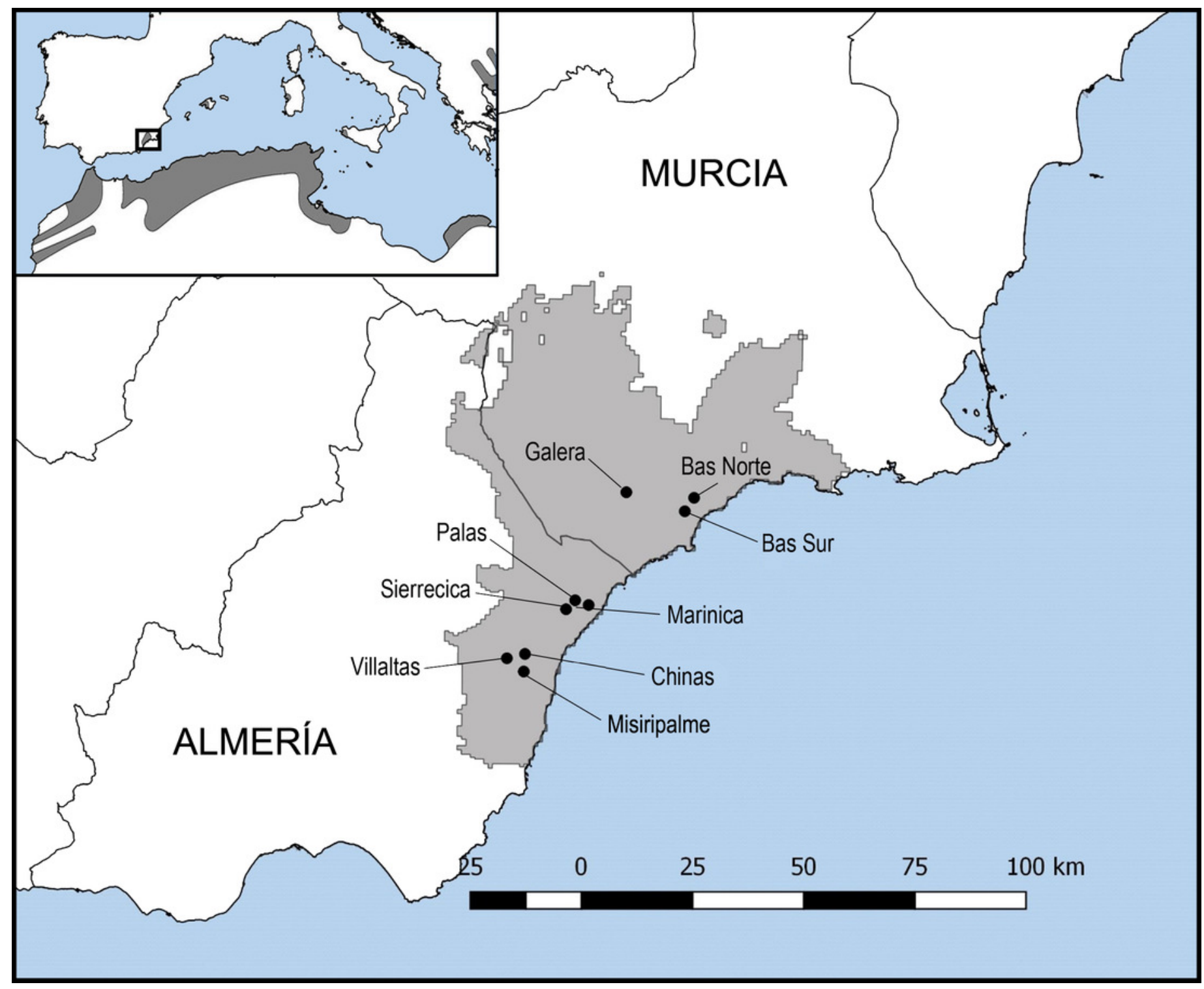




\section{Figure 2}

Relationship between oxyurid nematode species richness and abundance and tortoises'growth rates

Best-fit linear regressions, with $95 \%$ confidence intervals, between oxyurid nematode infestation (i.e., species richness and abundance) and tortoises' (Testudo graeca) growth rates in scrubland landscapes in southern Spain. Tortoises were present in landscapes sustaining different levels of habitat loss (low, intermediate and high). (A and B) Tortoise populations at all life stages. ( $C$ and D) Adult tortoise populations only. Significant relationships are indicated by $* P<0.01$ an/or $* * P<0.001$. The values for the linear regression equation $(y=a+b x)$ and the resulting $r$-values are indicated for each case. 
(a) All tortoises
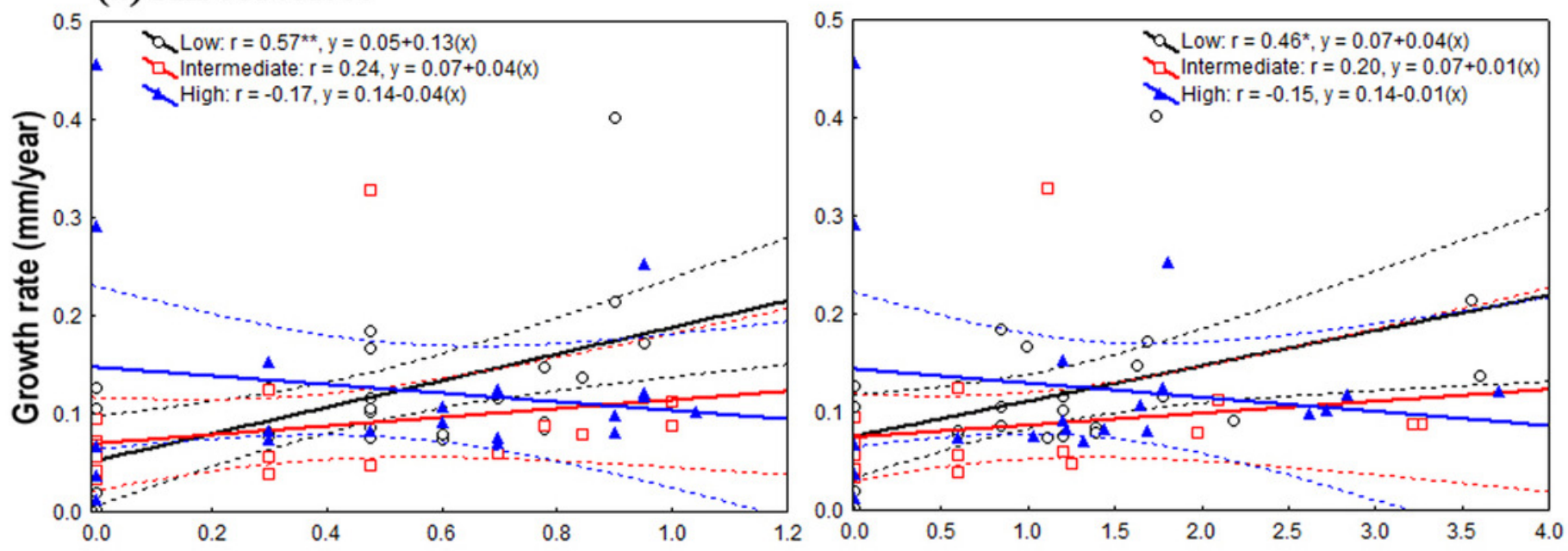

(b) Adult tortoises
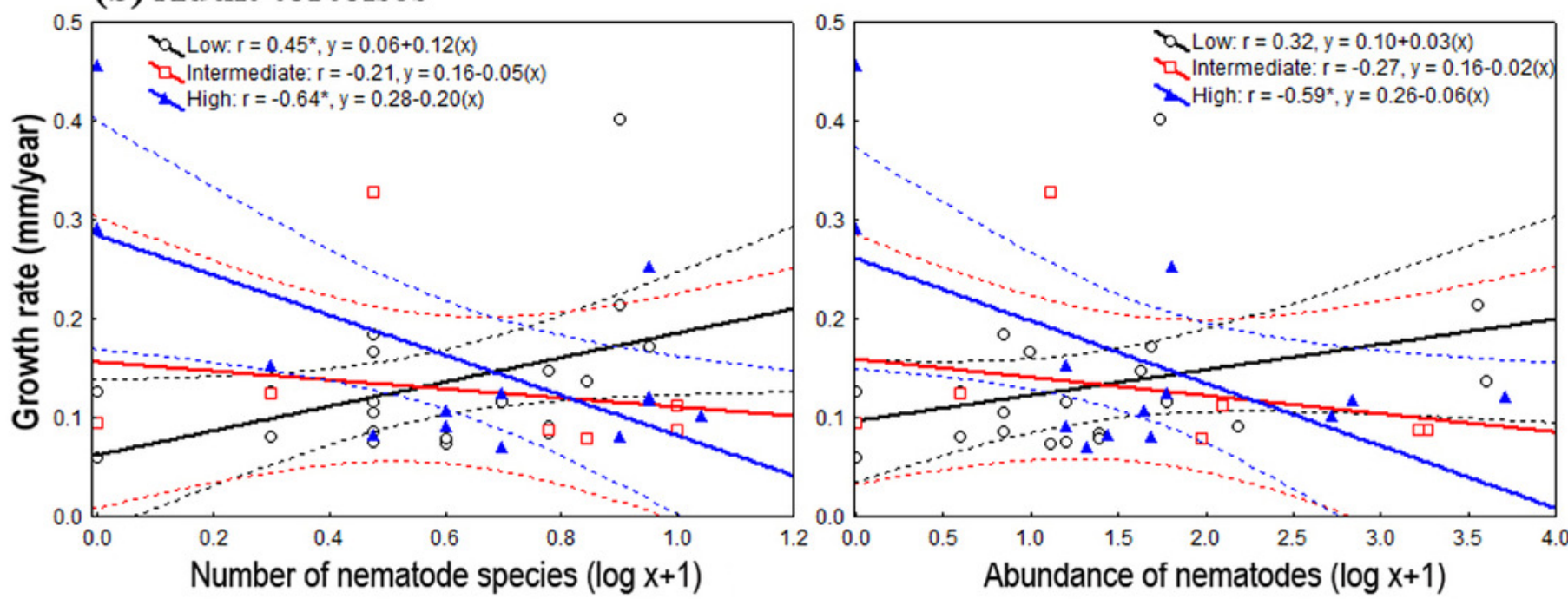


\section{Figure 3}

Rank/abundance oxyurid nematode species plots

Rank/abundance plots for the oxyurid nematode community infesting tortoises (Testudo graeca) in scrubland landscapes with different levels of habitat loss (low, intermediate and high) in southern Spain. For each landscape, the relative abundance of each nematode species is plotted on a logarithmic scale against the species' rank, from the most to the least abundant species. Nematodes included the following species: Alaeuris numidica (A. num), Mehdiella stylosa (M. styl), M. uncinata (M. unci), M. microstoma (M. micro), Tachygonetria longicollis ( $T$. long), $T$. dentata ( $T$. dent), $T$. conica ( $T$. coni), $T$. robusta ( $T$. rob), $T$. macrolaimus ( $T$. mac), T. numidica ( $T$. numi), $T$. setosa (T. set), T. palearticus ( $T$. pale), $T$. pusilla (T. pusi), and T. seurati (T. seur). Nematode species not found under all habitat loss conditions are in bold red.

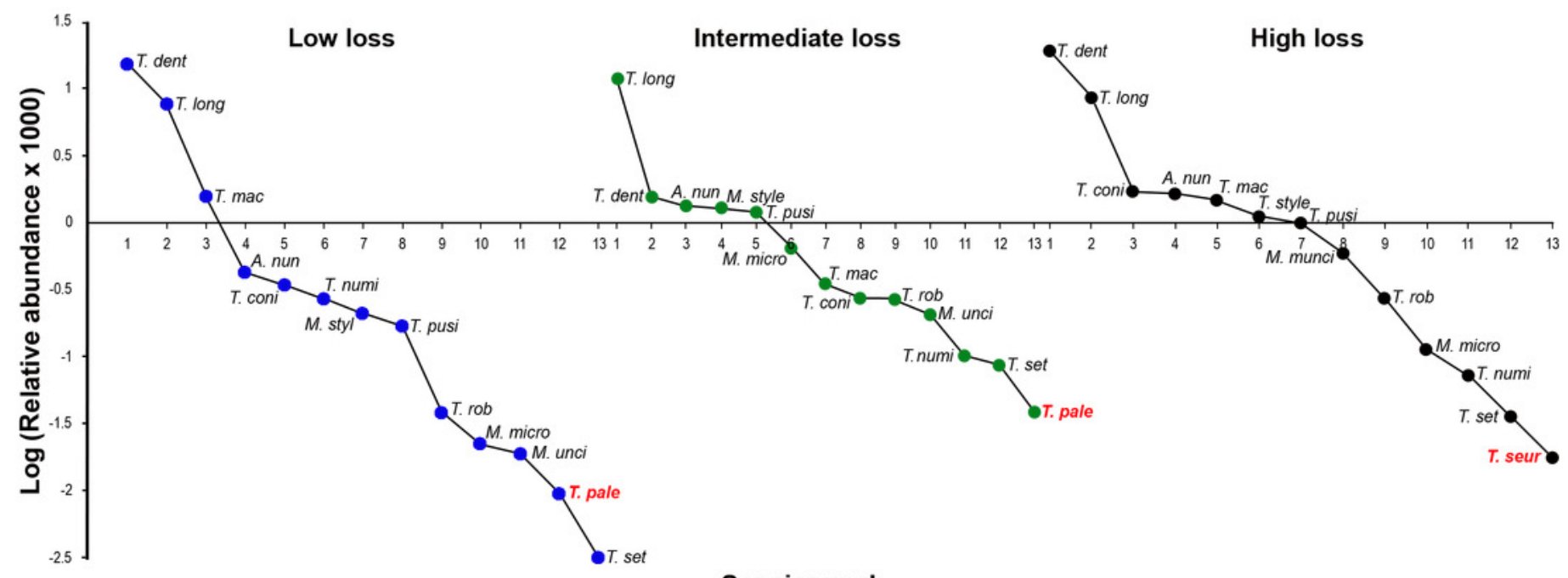

Species rank 


\section{Figure 4}

Quantitative bipartite plots of the tortoise-oxyurid species ecological networks encompassing different levels of habitat loss

Quantitative bipartite plots of the tortoise-oxyurid species ecological networks for each landscape encompassing different levels of habitat loss (low, intermediate and high) in southern Spain. (A) Tortoise- oxyurid ecological network at low habitat loss. (B) Tortoiseoxyurid ecological network at intermediate habitat loss. (C) Tortoise- oxyurid ecological network at high habitat loss. The bar size represents the number of interactions each oxyurid species (black) had with each individual tortoise (Testudo graeca) in the population (grey), and the linkage width represents the proportion of oxyurid individuals involved in such interactions. 

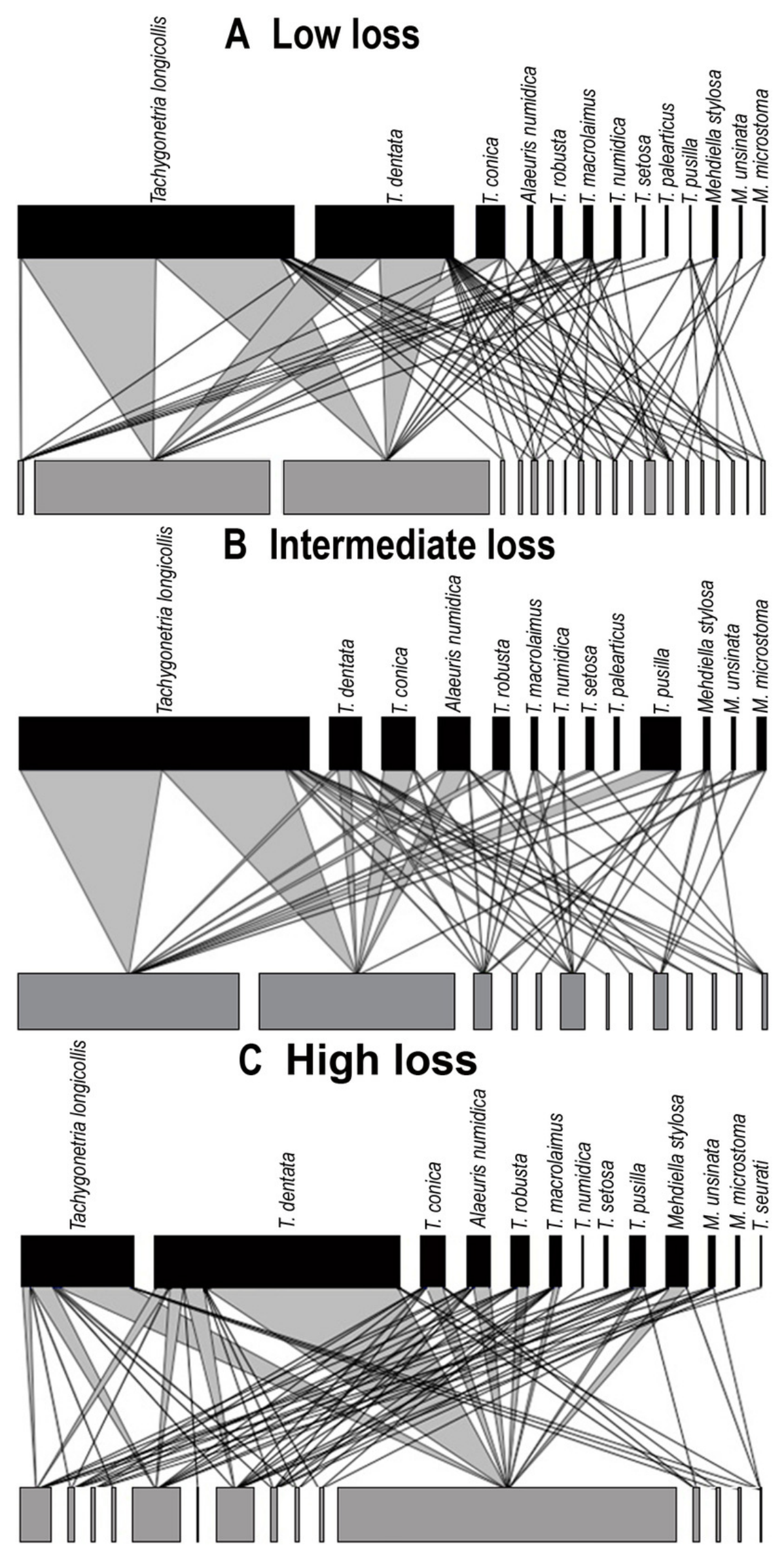

PeerJ reviewing PDF | (2018:11:33006:3:0:NEW 11 Oct 2019) 